\title{
Proposal of Thermoactinomyces mirandus sp. nov., a filamentous, anaerobic bacterium isolated from a biogas plant
}

\author{
Mira Mutschlechner $(\mathbb{D} \cdot$ Nina Lackner $\cdot$ Rudolf Markt • Willi Salvenmoser • \\ Christopher A. Dunlap • Andreas O. Wagner
}

Received: 2 October 2020/Accepted: 4 November 2020/Published online: 19 November 2020

(C) The Author(s) 2020

\begin{abstract}
We isolated a filamentous, thermophilic, and first anaerobic representative of the genus Thermoactinomyces, designated strain AMNI- ${ }^{\mathrm{T}}$, from a biogas plant in Tyrol, Austria and report the results of a phenotypic, genetic, and phylogenetic investigation. Strain AMNI- $1^{\mathrm{T}}$ was observed to form a white branching mycelium that aggregates into pellets when grown in liquid medium. Cells could primarily utilize lactose, glucose, and mannose as carbon and energy sources, with acetate accelerating and yeast extract being mandatory for growth. The optimum growth temperature and $\mathrm{pH}$ turned out to be $55^{\circ} \mathrm{C}$ and $\mathrm{pH}$ 7.0, respectively, with an optimum $\mathrm{NaCl}$ concentration of 0-2\% (w/v). 16S rRNA gene sequence comparison
\end{abstract}

Mira Mutschlechner and Nina Lackner have contributed equally to this work.

M. Mutschlechner $(\bowtie) \cdot$ N. Lackner .

R. Markt · A. O. Wagner

Department of Microbiology, Universität Innsbruck,

Technikerstraße 25d, 6020 Innsbruck, Austria

e-mail: Mira.Mutschlechner@uibk.ac.at

W. Salvenmoser

Department of Zoology, Universität Innsbruck,

Technikerstraße 25, 6020 Innsbruck, Austria

C. A. Dunlap

Crop Bioprotection Research Unit, Agricultural Research Service, US Department of Agriculture, National Center for Agricultural Utilization Research, Peoria,

IL 61604, USA indicated that the genetic relatedness between strain AMNI- $1^{\mathrm{T}}$ and Thermoactinomyces intermedius, Thermoactinomyces khenchelensis, and Thermoactinomyces vulgaris was less than $97 \%$. The $\mathrm{G}+\mathrm{C}$ content of the genomic DNA was $44.7 \mathrm{~mol} \%$. The data obtained suggest that the isolate represents a novel and first anaerobic species of the genus Thermoactinomyces, for which the name Thermoactinomyces mirandus is proposed. The type strain is AMNI$1^{\mathrm{T}}\left(=\mathrm{DSM} 110094^{\mathrm{T}}=\right.$ LMG $\left.31503^{\mathrm{T}}\right)$. The description of the genus Thermoactinomyces is emended accordingly.

Keywords Hydrogen production - Thermophilic . $\mathrm{NiFe} \cdot$ Hydrogenase $\cdot$ Hyp $\cdot$ Novobiocin .

Thermoactinomycetaceae $\cdot$ Fermentation

\section{Introduction}

The genus Thermoactinomyces within the family Thermoactinomycetaceae was initially described by Tsilinsky (1899), with the first known representative Thermoactinomyces vulgaris being isolated from decaying straw and manure. Since then, several species of Thermoactinomyces have been isolated from a variety of habitats (Bezuidt et al. 2016). In 2005, several former Thermoactinomyces species were reclassified in new genera Laceyella, Thermoflavimicrobium and Seinonella (Yoon et al. 2005). 
Currently, the genus comprises four validly described species including Thermoactinomyces vulgaris (Tsilinsky 1899), Thermoactinomyces intermedius (Kurup et al. 1980), Thermoactinomyces daqus (Yao et al. 2014), and Thermoactinomyces khenchelensis (Mokrane et al. 2016). All these species are aerobic, Gram-positive, chemoorganotrophic, filamentous, thermophilic bacteria with a $\mathrm{G}+\mathrm{C}$ content in the range of 48.0-49.1 mol\% (Lacey and Cross 1989). Aerial mycelium is abundant and white. Well-developed, branched and septate substrate mycelium is formed.

Here we describe strain AMNI- $1^{\mathrm{T}}$ that was isolated from a biogas plant. Although sharing certain common phenotypic and genotypic characteristics to members of the genus Thermoactinomyces including filamentous growth, resistance to novobiocin, and 16S rRNA gene sequence similarity, the novel strain AMNI- ${ }^{\mathrm{T}}$ requires anaerobic conditions for its fermentative metabolism in contrast to its closest relatives. Therefore, we propose that strain AMNI- ${ }^{\mathrm{T}}$ should be classified as a novel species and first anaerobic representative of the genus Thermoactinomyces. As a consequence, the genus should be emended to include anaerobic members with a fermentative, acid and hydrogen producing metabolism.

\section{Materials and methods}

Isolation and ecology

Strain AMNI-1 ${ }^{\mathrm{T}}$ was isolated from a biogas plant located in Roppen (Tyrol, Austria, 47.230 N 10.833 E) in 2015. The anaerobic digestion plant represents a 750.000-L plug-flow digester that is operated under thermophilic conditions and designed to treat separately gathered organic fractions of household wastes (Wagner et al. 2018). For a description of running parameters and physical-chemical properties of the reactor please refer to (Illmer et al. 2009). Fermenter sludge samples were withdrawn from the inlet of the biogas reactor via a sampling port by removing approx. $1 \mathrm{~kg}$ of sludge, diluted and incubated under thermophilic conditions as described previously (Wagner et al. 2014) and subsequently used as inoculum by multiple transfers into deep agar shakes. One isolate, which we designated as AMNI- ${ }^{\mathrm{T}}$, was selected for further characterization. After isolation, strain AMNI-1 ${ }^{\mathrm{T}}$ was repeatedly transferred in fresh liquid media as described below by particularly selecting visible white filaments.

\section{Physiological characterization}

The medium used for long-term maintenance of the pure culture contained (in $\mathrm{g} \mathrm{L}^{-1}$ ): $0.35 \mathrm{~K}_{2} \mathrm{HPO}_{4}, 0.23$ $\mathrm{KH}_{2} \mathrm{PO}_{4}, 0.5 \mathrm{MgSO}_{4} \cdot 7 \mathrm{H}_{2} \mathrm{O}, 0.05 \mathrm{CaCl}_{2} \cdot 2 \mathrm{H}_{2} \mathrm{O}, 2.25$ $\mathrm{NaCl}, 0.002 \quad \mathrm{FeSO}_{4} \cdot 7 \quad \mathrm{H}_{2} \mathrm{O}, 0.5 \quad \mathrm{NH}_{4} \mathrm{Cl}, 1.0$ yeast extract, 2.0 lactose, 0.5 sodium acetate, and $0.5 \mathrm{~L}-$ cysteine $\mathrm{HCl}$. After solving all ingredients, the medium was amended with $1.0 \mathrm{~mL}$ SL-10 (Medium 120, German Collection of Microorganisms and Cell Cultures $\mathrm{GmbH})$ and $1 \mathrm{~mL}$ resazurin $(0.1 \% \mathrm{w} / \mathrm{v})$, with the $\mathrm{pH}$ being adjusted to 6.8 , if not indicated otherwise. Aliquots of $50 \mathrm{~mL}$ were filled in $120 \mathrm{~mL}$ serum flasks and heated in a water bath for $20 \mathrm{~min}$ to reduce the solubility of $\mathrm{O}_{2}$. The headspaces were immediately flushed with $\mathrm{N}_{2}$, closed with butyl rubber septa, and sealed with aluminium caps. Before autoclaving, $0.5 \mathrm{~mL} \mathrm{Na} \mathrm{S}_{2}\left(12.0 \mathrm{~g} \mathrm{~L}^{-1}\right)$ together with $\mathrm{NaHCO}_{3}\left(50.0 \mathrm{~g} \mathrm{~L}^{-1}\right)$ solution was added to each flask to decrease the redox potential and as buffering agent (Wagner et al. 2019). The medium was inoculated with $1 \mathrm{~mL}$ of active cultures (less than $36 \mathrm{~h}$ of age as the viability decreases with time) and incubated at $55^{\circ} \mathrm{C}$, if not indicated otherwise. For single parameter variation studies, the concentration of yeast extract was reduced to $0.1 \mathrm{~g} \mathrm{~L}^{-1}$.

Growth was determined after 3 days of incubation via visible growth and evaluation of $\mathrm{H}_{2}$ and $\mathrm{CO}_{2}$ production via gas chromatography by applying a thermal conductivity detector as described previously (Wagner et al. 2011). For positive growth, twice the mean of the controls (containing only $0.1 \mathrm{~g} \mathrm{~L}^{-1}$ as sole carbon source) was set as threshold for $\mathrm{H}_{2}$ and $\mathrm{CO}_{2}$ production. The fermentation products were detected and quantified using high performance liquid chromatography according to Wagner et al. (2017). The $\mathrm{pH}$ was measured with MColorpHast ${ }^{\mathrm{TM}}$ indicator stripes (Merck Millipore, Germany). Regarding chemotaxonomic characterisation, fatty acid methyl ester (FAME) profiling as proof of relationship seemed unreasonable due to the anaerobic nature of the strain in contrast to its aerobic nearest neighbours.

The temperature range for growth was evaluated by incubating the isolate at $25-65{ }^{\circ} \mathrm{C}(25,30,37,45,50$, 55,60 , and $65^{\circ} \mathrm{C}$ for 7 days). Growth was further 
tested at different initial $\mathrm{pH}$ values ranging from $\mathrm{pH}$ 5.0 to 9.0 (by adjusting with $1.0 \mathrm{M} \mathrm{HCl}$ and $1.0 \mathrm{M}$ $\mathrm{NaOH}$, respectively) and $\mathrm{NaCl}$ concentrations of 0 , $0.225,1.0,2.0,5.0$, and $10.0 \%(\mathrm{w} / \mathrm{v})$. Antibiotic testing of the strain was performed in the presence of novobiocin, streptomycin, ampicillin, gentamycin, chloramphenicol, tetracycline, and erythromycin (5 $\mu \mathrm{g} \mathrm{mL}^{-1}$ each). Carbon sources were tested at a concentration of $0.8 \mathrm{~g} \mathrm{C} \mathrm{L} \mathrm{L}^{-1}$ (please see below). Aerobic growth was tested in the same medium by enriching the headspace with varying concentrations of $\mathrm{O}_{2}$.

\section{Phenotypic characterization}

The morphological characteristics of strain AMNI- ${ }^{\mathrm{T}}$ were observed by light microscopy (Nikon Eclipse) as well as scanning (SEM) and transmission electron microscopy (TEM) (Zeiss, Germany) after incubation of 4 and 35 days. For SEM, samples were fixed with $2.5 \%$ glutaraldehyde in $0.1 \mathrm{M}$ cacodylate buffer, washed in buffer and postfixed in $1 \%$ osmium tetroxide in $0.05 \mathrm{M}$ cacodylate buffer. After washing with buffer, samples were dehydrated with an increasing ethanol series and critical point dried with an EMS 850 CPD (Electron Microscopy services, Germany). After mounting, $20 \mathrm{~nm}$ gold were sputtered onto the samples with a CCD-10 sputter coater (Safematic, Switzerland) and examined with a Zeiss DSM950 SEM (Zeiss, Germany). Images were taken with a Pentax digital camera and a PK_Tether 0.7.0 free software. For TEM, specimens were fixed with $2.5 \%$ glutaraldehyde in culture medium for $1 \mathrm{~h}$ at $4{ }^{\circ} \mathrm{C}$, washed in $0.1 \mathrm{M}$ cacodylate buffer and postfixed with $1 \%$ osmium tetroxide in $0.05 \mathrm{M}$ cacodylate buffer for $1 \mathrm{~h}$. Stain AMNI- ${ }^{\mathrm{T}}$ was dehydrated in an increasing acetone series and embedded into EMBed 812 epoxy resin. Sections were cut with a diamond knife (Diatome, Switzerland) on an Ultracut UCT ultramicrotome (Leica, Vienna), stained with lead citrate and examined with a Zeiss Libra 120 TEM (Zeiss, Germany). Images were taken with Image SP software and a high-speed $2 \times 2 \mathrm{k}$ camera (Tröndle, Germany).

Phylogenetic analyses

The genomic DNA was extracted using a NucleoSpin ${ }^{\circledR}$ Soil kit (Macherey-Nagel, Germany) according to the manufacturers protocol. Initially, the 16S rRNA gene was amplified using the universal primers 27f and 1492r (Heuer et al. 1997). Sanger sequencing was performed at Eurofins Genomics (Germany). Sequencing data were deposited in GenBank (accession number: MN148883). Subsequently, the genome of the strain and two close relatives (Thermoactinomyces vulgaris KACC $12356^{\mathrm{T}}$ and Thermoactinomyces intermedius NRRL B-16979 ${ }^{\mathrm{T}}$ ) were sequenced to definitively confirm the taxonomy of the strain. The genomic DNA was prepared for sequencing using Nextera XT library preparation kit following the manufacturer's suggested protocols. The prepared libraries were sequenced using a MiSeq DNA sequencer with the MiSeq V3 2x300 sequencing kit. The resulting reads were quality trimmed to the $95 \%$ confidence level. The draft genome was assembled using CLCbio Genomics Workbench 20.0 (Qiagen Inc, Cambridge, MA) using default parameters. The sequences for the subject strain, AMNI- $1^{\mathrm{T}}$ were deposited in NCBI Genbank under accession numbers JACEOL010000000 and a full length 16S rRNA was deposited under GenBank accession number JACEOL010000098. The sequences for $T$. vulgaris KACC $12356^{\mathrm{T}}$ and $T$. intermedius NRRL B-16979 ${ }^{\mathrm{T}}$ ) were submitted to NCBI Genbank under accession numbers JACEOK010000000 and JACETT010000000, respectively.

The 16S rRNA phylogeny of the strain was performed using the genome derived 16S rRNA gene. Close relatives were identified using EZBioCloud 16S rRNA database (Yoon et al. 2017) and alignments were made with MEGA X. The Maximum-Likelihood tree was determined using the Tamura-Nei model (gamma distributed with invariant sites) based on model testing under MEGA X (Kumar et al. 2018). Aneurinibacillus aneurinilyticus was selected as an outgroup. Measures of bootstrap support for internal branches were obtained from 1500 pseudoreplicates. Additionally, a 92 gene nucleotide phylogeny was performed using UBCG software with default parameters using FastTree (Na et al. 2018). In addition to the genomes of all available type strains in the area, all genomes from representative strains from Thermoactinomyces and Laceyella genera were included. The average nucleotide identity (ANI) was determined using OrthoANI using default parameters on the website (Lee et al. 2016). 


\section{Results and discussion}

Physiological and morphological characterization

Results of the physiological characterization are summarized in Table 1. Strain AMNI- ${ }^{\mathrm{T}}$ grew well on lactose, glucose, mannose, or lactose/acetate. Poor growth was observed when yeast extract or meat extract were the main carbon sources. Small amendments of yeast extract; however, were mandatory for growth on all substrates. Further, $1.0 \mathrm{~g}$ acetate $\mathrm{L}^{-1}$ accelerated growth. Substrates that could not be utilized included glycine, alanine, sucrose, methanol, ethanol, starch, peptone, lactate, and $\mathrm{H}_{2} / \mathrm{CO}_{2}$. In the presence of $0.1 \mathrm{~g} \mathrm{~L}^{-1}$ yeast extract, the end products of lactose fermentation were lactate, acetate, ethanol, $\mathrm{H}_{2}$ and $\mathrm{CO}_{2}$. Strain AMNI-1 ${ }^{\mathrm{T}}$ showed growth at temperatures ranging from 45 to $60{ }^{\circ} \mathrm{C}$ (Fig. 1) and at $\mathrm{pH}$-values ranging from 5.0 to 9.0 , optimal growth occurred at $55^{\circ} \mathrm{C}$ and $\mathrm{pH} 7.0$, respectively. The optimal $\mathrm{NaCl}$ concentration turned out to be in the range of $0-2.0 \%(\mathrm{w} / \mathrm{v})$. The study of antibiotic susceptibility showed that strain AMNI- $1^{\mathrm{T}}$ was sensitive to a wide range of antibiotics including chloramphenicol, tetracycline, ampicillin, streptomycin, gentamycin, and erythromycin but not to novobiocin, which is a common characteristic feature of Thermoactinomyces species. Strain AMNI- $1^{\mathrm{T}}$ was unable to grow under microaerophilic and aerobic conditions. Once growth occurred, $\mathrm{H}_{2}$ production as well as increased $\mathrm{CO}_{2}$ concentrations were detectable (Fig. 1).

Irrespective of shaking, strain AMNI- $1^{\mathrm{T}}$ formed white cloudy aggregates being able to float during phases of high gas production that were macroscopically visible. Light microscopy and SEM/TEM revealed hyphae like structures of approximately $0.3-0.5 \mu \mathrm{m}$ diameter. The mycelium consisted of branched, septate, and corrugated filamentous structures (Fig. 2a-c).

The cell wall contains a meso-diaminopimelate peptidyl-glycan linkage based on comparisons of the peptidyl glycan ligase (MBA4601166.1) found in the subject strain and closely related types strains with verified linkages. Comparisons of cell wall fatty acids with closely related types strains was not performed, since suitable common growth conditions (aerobic vs. anaerobic) could not be identified. Fatty acids have not been used as distinguishing phenotypes in the taxonomy of Thermoactinomyces species.

Phylogenetic interference and genome features

The 16S rRNA phylogeny has low bootstrap support for many of the branches (Fig. 3). While the UBCG 92 gene tree has high support for all branches (Fig. 4).

Table 1 Differential characteristics of strain AMNI-1 ${ }^{\mathrm{T}}$ and type strains of the genera Thermoactinomyces with an identity $>96 \%$

\begin{tabular}{|c|c|c|c|c|}
\hline Characteristics & 1 & 2 & 3 & 4 \\
\hline \multicolumn{5}{|l|}{ Utilization of } \\
\hline Glycine & - & - & nd & - \\
\hline Glucose & + & - & + & - \\
\hline Lactose & + & - & - & + \\
\hline Starch & - & nd & nd & - \\
\hline Resistance to novobiocin & + & + & + & + \\
\hline Growth in the presence of $5 \% \mathrm{NaCl}(\mathrm{w} / \mathrm{v})$ & - & nd & + & - \\
\hline Temperature range $\left({ }^{\circ} \mathrm{C}\right)$ & $45-60$ & $37-65$ & $37-55$ & $45-60$ \\
\hline $\mathrm{G}+\mathrm{C}$ content $(\mathrm{mol} \%)$ & 44.7 & 48 & nd & 48 \\
\hline $\mathrm{pH}$ range & $5.0-9.0$ & $5.0-8.0$ & $7.0-9.0$ & $5.0-8.0$ \\
\hline $\mathrm{O}_{2}$ requirements & Anaerobic & Aerobic & Aerobic & Aerobic \\
\hline Endospores & Not observed & + & + & + \\
\hline
\end{tabular}

Strains: 1 , AMNI-1 ${ }^{\mathrm{T}} ; 2$, T. intermedius DSM $43846^{\mathrm{T}} ; 3$, T. khenchelensis DSM $45951^{\mathrm{T}} ;$ 4, T. vulgaris DSM $43016^{\mathrm{T}}$. Data on strain AMNI- $1^{\mathrm{T}}$ were determined in this study; data on 2, 3, and 4 were obtained from Kurup et al. (1980), Mokrane et al. (2016), and Tsilinsky (1899). +, positive; -, negative; $n d$ not determined 


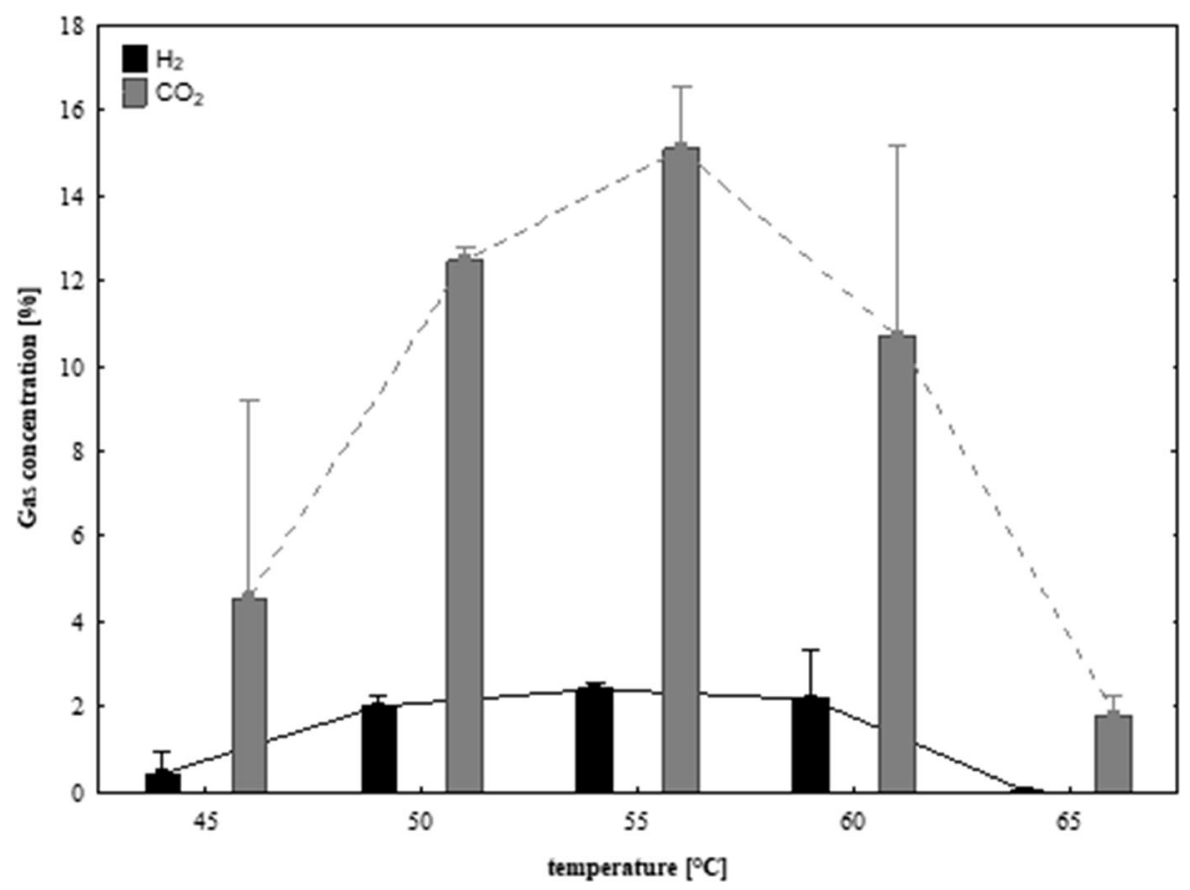

Fig. $1 \mathrm{H}_{2}$ and $\mathrm{CO}_{2}$ concentration quantified via gas chromatography (GC-TCD) in serum flasks with strain AMNI-1 ${ }^{\mathrm{T}}$ at different incubation temperatures. Results are given as mean $( \pm \mathrm{SD}), \mathrm{n}=3$
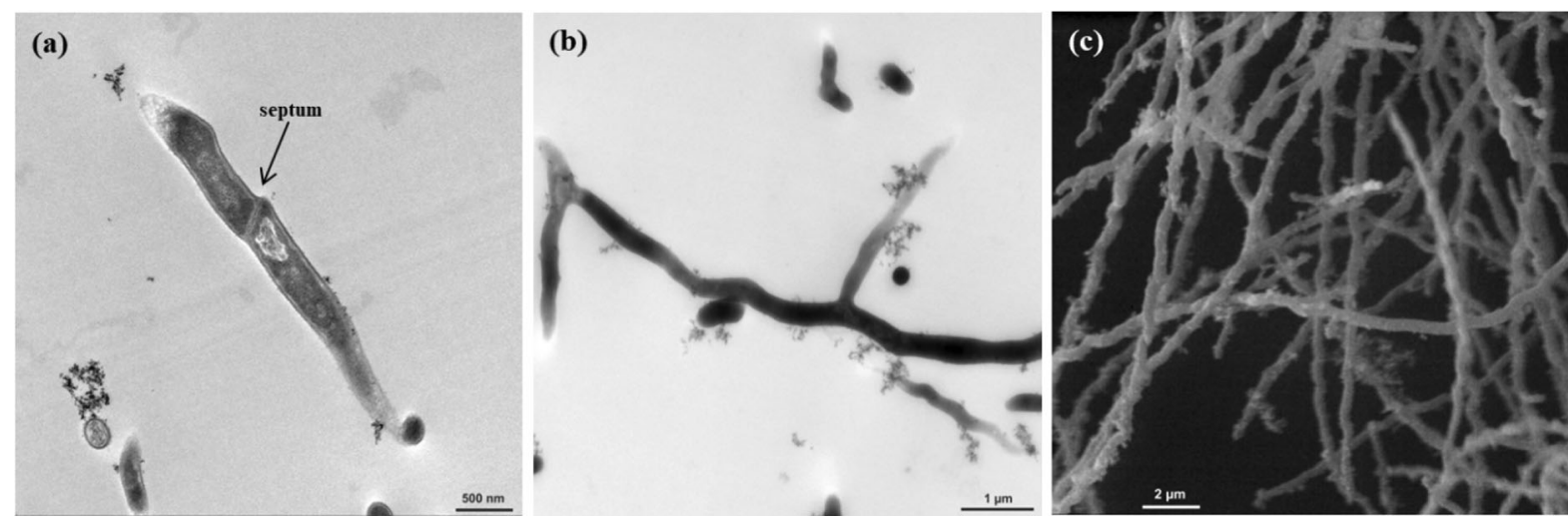

Fig. 2 Transmission electron microscopy of strain AMNI- $1^{\mathrm{T}}$ after 4 days (a) and 35 days (b). Scanning electron microscopy of strain AMNI- ${ }^{\mathrm{T}}$ after 4 days (c)

There are some incongruences between the 16S rRNA and UBCG tree in the areas of the 16S rRNA gene tree with low bootstrap support. The inclusion of the representative (non-type) genomes showed some inconsistencies in the taxonomy they were accessioned under. Two strains (Genbank accession\#: JPZM01 and LSVF01) accessioned under Thermoactinomyes sp. should be T. vulgaris. Two strains (Genbank accession\#: FNLP01 and FNJZ01) accessioned under Thermoactinomyes sp. should be Risungbinella sp. Strain NRRL F-5595 (Genbank accession\#: LGKI01) accessioned under T. vulgaris sp. should be Laceyella sacchari. Our results are also consistent with Laceyella tengchongensis being a later heterotypic synonym of Laceyella sedeminis as recently reported (Jiang et al. 2019). No public genomes were found to be conspecific with the subject strain. Average nucleotide identity analysis of the type 
strains in this area confirmed strain $\mathrm{AMNI}-1^{\mathrm{T}}$ was a novel species with the closest type strain having an ANI of 74.0 (Fig. 5). The $\mathrm{G}+\mathrm{C}$ content of the DNA was determined from the genome data. The DNA $\mathrm{G}+\mathrm{C}$ content of strain AMNI-1 ${ }^{\mathrm{T}}$ was $44.7 \mathrm{~mol} \%$, which is lower compared with its closest phylogenetic relatives (Table 1).

After quality trimming, Sanger sequencing of the 16S rRNA gene yielded a consensus sequence of $1365 \mathrm{bp}$, which was aligned to the 16S rRNA database. The maximum likelihood analysis of the resulting alignment (1352 bp) placed strain AMNI- ${ }^{\mathrm{T}}$ in the family Thermoactinomycetaceae, with the strain forming a common clade with species of the genus Thermoactinomyces. The closest relatives are $T$. intermedius, T. khenchelensis, and T. vulgaris, with sequence identities of $96.3 \%, 96.2 \%$, and $96.2 \%$, respectively. Based on its phenotypic and genotypic
Fig. 4 Genome-based phylogenetic tree showing the relationships of strain AMNI- $1^{\mathrm{T}}$ to members of related species. The tree was based on 92 genes in the up-to-date bacterial core genome (UBCG) (Na et al. 2018). The maximum likelihood tree was produced by FastTree under the default parameters in the UBCG pipeline. Bar represents expected numbers of substitutions per nucleotide position

characteristics, strain AMNI- $1^{\mathrm{T}}$ should be described as a novel species belonging to the Thermoactinomyces genus, for which the name Thermoactinomyces mirandus sp. nov. is proposed. The type strain is AMNI- ${ }^{\mathrm{T}}$ (= DSM $110094^{\mathrm{T}}=$ LMG $31503^{\mathrm{T}}$ ).

Genome sequencing showed that strain AMNI- $1^{\mathrm{T}}$ encodes an 11 gene cluster for a structural [NiFe]hydrogenase and its assembly as well as maturation (locus_tags: H2C83.05685..H2C83.05735), which was rather surprising as none of these particular genes

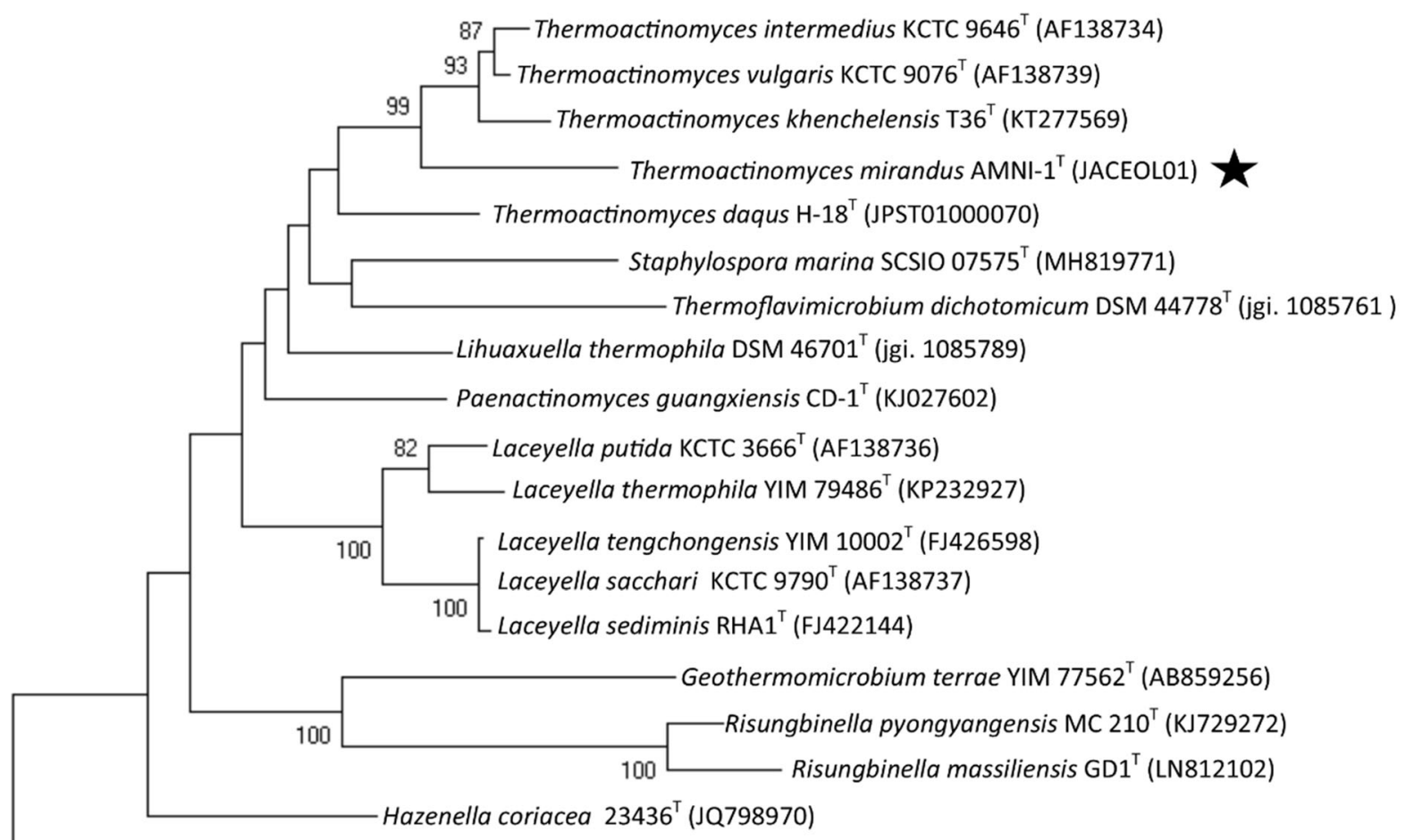

Aneurinibacillus aneurinilyticus ATCC $12856^{\top}$ (D78455)

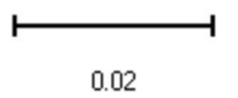

Fig. 3 Phylogenetic tree showing the relationships of strain AMNI- $1^{\mathrm{T}}$ to members of related species. The tree was based on 16S rRNA gene sequences obtained from EzBioCloud reference database. Clustering was performed with maximum likelihood using the Tamura-Nei substitution model as determined through model testing under MEGA X. Bootstrap support was calculated based on 1500 pseudoreplicates and values below 70\% are removed. Bar represents expected numbers of substitutions per nucleotide position 


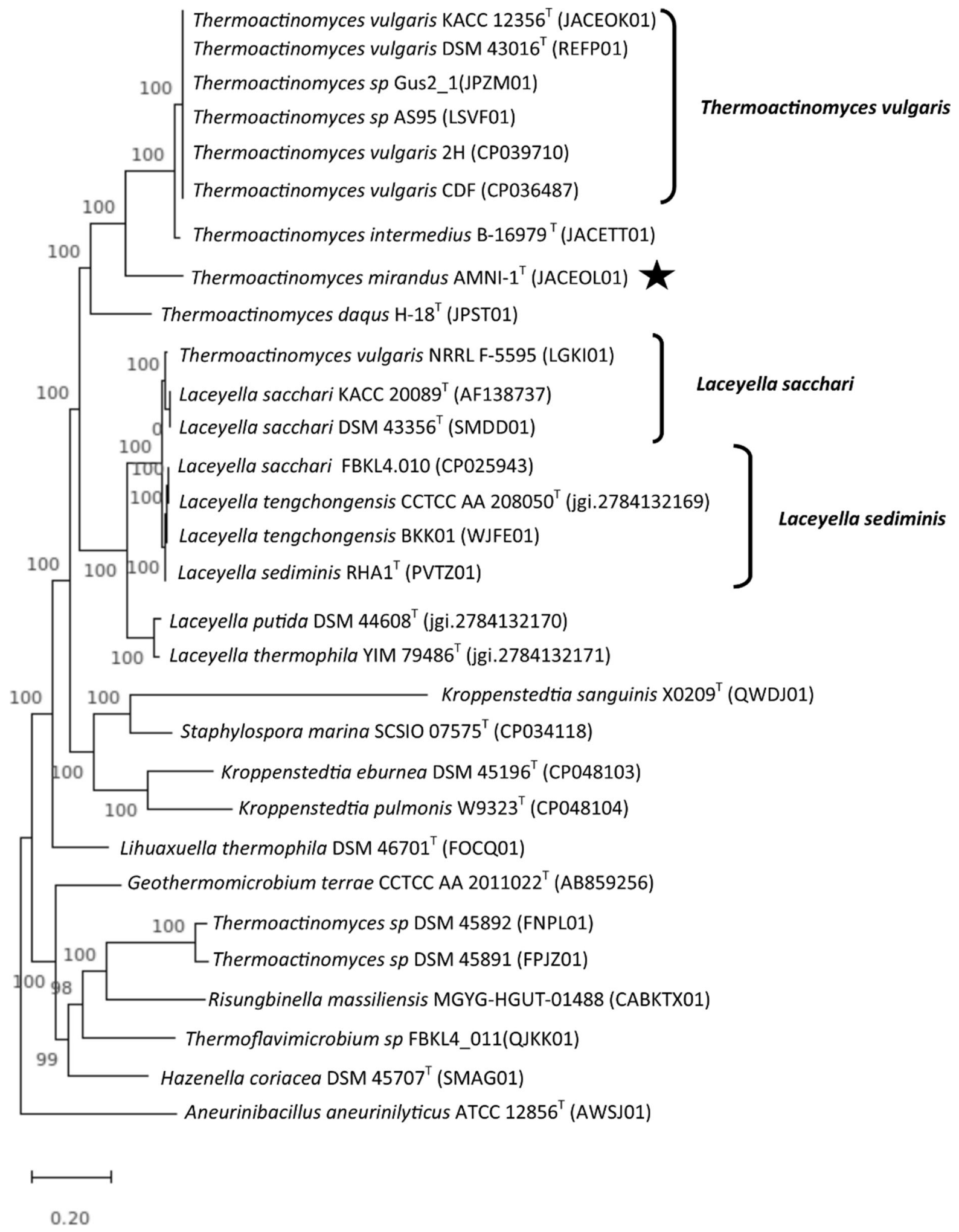




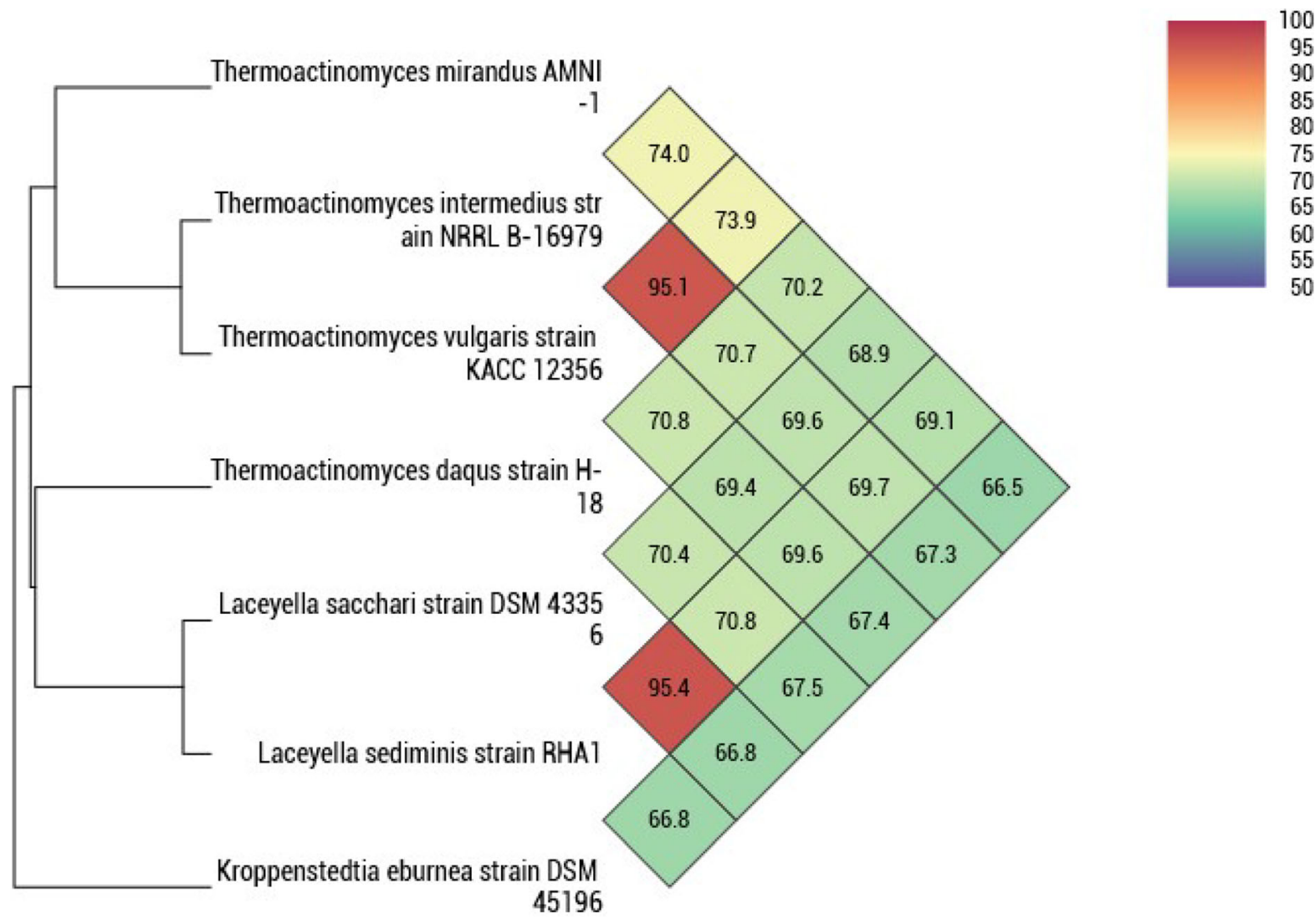

Fig. 5 Average nucleotide identity analysis of closely related type strains

have been identified in any other, already sequenced species of the family Thermoactinomycetaceae. [NiFe] hydrogenases represent a diverse group of metalloenzymes that catalyse reversible hydrogen production/consumption $\left(\mathrm{H}_{2}<->2 \mathrm{H}++2 \mathrm{e}-\right)$ (Teng et al. 2019; Marshall et al. 2012), thus coinciding with our GC analyses revealing hydrogen formation (Fig. 1). The biosynthesis/maturation of these enzymes constitutes a complex process that involves six Hyp proteins, all of which have been found in the present investigation (HypABCDEF). While the accessory protein HypB is associated with the insertion of $\mathrm{Ni}$, HypCDEF proteins are responsible for the biosynthesis, assembly and insertion of the $\mathrm{Fe}(\mathrm{CN})_{2} \mathrm{CO}$ group (Watanabe et al. 2012). Among the three major classes (i.e. [Fe]-, $[\mathrm{FeFe}]$-, and [NiFe]hydrogenases), most known thermotolerant hydrogenases contain a [NiFe] active site and can be found within the domain of (aerobic and anaerobic) Bacteria and Archaea (Eberly and Ely 2008; Peters et al. 2015). Genome sequencing further showed the presence of genes associated with fermentation (lactate and mixed acid fermentation) and mannose metabolism, which is consistent with our data on utilized carbon sources (Table 1).

Emended description of the genus Thermoactinomyces Tsiklinsky 1899 (Approved Lists 1980) emend. Yoon et al. (2005)

The description is as given by Yoon et al. (2005) with the following modifications. The genus includes aerobic as well as anaerobic members. Anaerobic fermentative metabolism involves the production of acids and hydrogen. The $\mathrm{G}+\mathrm{C}$ content may range from 44.7 to $49.1 \mathrm{~mol} \%$. The genus includes a new species, T. mirandus. 
Description of Thermoactinomyces mirandus sp. nov.

Thermoactinomyces mirandus (mir.an'dus. L. masc. adj. (gerundive of L. v. miror), to be admired).

Thermoactinomyces mirandus forms a white branching, septate mycelium that aggregates into pellets in liquid culture. T. mirandus requires anaerobic conditions and grows well on lactose, lactose/ acetate, mannose, and glucose, whereas growth on yeast and meat extract is poor. Small amendments of yeast extract; however, are mandatory for growth. A combination of lactose and acetate accelerates growth. Products from lactose fermentation are lactate, acetate, ethanol, $\mathrm{H}_{2}$ and $\mathrm{CO}_{2}$. Growth occurs in the range of $45-60{ }^{\circ} \mathrm{C}$ and $\mathrm{pH}$ 5.0-9.0, with optima at $55{ }^{\circ} \mathrm{C}$ and $\mathrm{pH} 7.0$, respectively (Table 1). The optimal $\mathrm{NaCl}$ concentration is $0-2 \%(\mathrm{w} / \mathrm{v})$. T. mirandus has a $\mathrm{G}+\mathrm{C}$ content of $44.7 \mathrm{~mol} \%$.

The type strain, AMNI- ${ }^{\mathrm{T}}$ (= DSM $110094^{\mathrm{T}-}$ $=$ LMG $31503^{\mathrm{T}}$ ), was isolated from a thermophilic biogas plant in Roppen (Tyrol, Austria). The GenBank accession number is: MN148883.

Acknowledgements We greatly thank Prof. Rosa Margesin and Eva Maria Prem for their support. Any opinions, findings, conclusions, or recommendations expressed in this publication are those of the author(s) and do not necessarily reflect the view of the U.S. Department of Agriculture. The mention of firm names or trade products does not imply that they are endorsed or recommended by the USDA over other firms or similar products not mentioned. USDA is an equal opportunity provider and employer.

Author contributions MM and AOW conceived the project. MM, NL, RM, and AOW performed the experiments. MM, NL, RM, WS, CAD and AOW analysed the data. MM, NL, WS, and CAD drafted the manuscript. All authors have read and approved the manuscript.

Funding Open access funding provided by Univerität Innsbruck. This study was financially supported by the Austrian Science Fund FWF (Project Number: P 29360).

Availability of data and materials The GenBank accession number of strain AMNI- ${ }^{\mathrm{T}}$ is MN148883. The type strain AMNI- $1^{\mathrm{T}}$ can be obtained from the German Collection of Microorganisms and Cell Cultures GmbH (DSM 110094 ${ }^{\mathrm{T}}$ ) and the Belgian Co-ordinated Collections of Micro-organisms $\left(\right.$ LMG $31503^{\mathrm{T}}$ ).

\section{Compliance with ethical standards}

Conflict of interest The authors declare that they have no conflict of interest.
Open Access This article is licensed under a Creative Commons Attribution 4.0 International License, which permits use, sharing, adaptation, distribution and reproduction in any medium or format, as long as you give appropriate credit to the original author(s) and the source, provide a link to the Creative Commons licence, and indicate if changes were made. The images or other third party material in this article are included in the article's Creative Commons licence, unless indicated otherwise in a credit line to the material. If material is not included in the article's Creative Commons licence and your intended use is not permitted by statutory regulation or exceeds the permitted use, you will need to obtain permission directly from the copyright holder. To view a copy of this licence, visit http://creativecommons.org/licenses/by/4.0/.

\section{References}

Bezuidt OKI, Gomri MA, Pierneef R, van Goethem MW, Kharroub K et al (2016) Draft genome sequence of Thermoactinomyces sp. strain AS95 isolated from a Sebkha in Thamelaht, Algeria. Stand Genom Sci 11:68

Eberly JO, Ely RL (2008) Thermotolerant hydrogenases: biological diversity, properties, and biotechnological applications. Crit Rev Microbiol 34:117-130

Heuer H, Krsek M, Baker P, Smalla K, Wellington EMH (1997) Analysis of actinomycete communities by specific amplification of genes encoding 16S rRNA and gel-electrophoretic separation in denaturing gradients. Appl Environ Microbiol 63:3233-3241

Illmer P, Schwarzenauer T, Malin C, Wagner AO, Miller LM et al (2009) Process parameters within a 750,000 litre anaerobic digester during a year of disturbed fermenter performance. Waste Manag 29:1838-1843

Jiang Z, Xiao M, Yang LL, Zhi XY et al (2019) Genome-based taxonomic classification within the family Thermoactinomycetaceae. Int J Syst Evol Microbiol 69:2028-2036

Kumar S, Stecher G, Li M, Knyaz C, Tamura K (2018) MEGA $\mathrm{X}$ : molecular evolutionary genetics analysis across computing platforms. Mol Biol Evol 35:1547-1549

Kurup VP, Hollick G, Pagan E (1980) Thermoactinomyces intermedius, a new species of amylase negative thermophilic actinomycetes. Science-Ciencia Bol Cien Sur 7:104-108

Lacey J, Cross T (1989) Genus Thermoactinomyces Tsiklinsky $1899,501^{\mathrm{AL}}$. In: Williams ST, Sharpe ME, Holt JG (eds) Bergey's manual of systematic bacteriology, vol 4. Williams \& Wilkins, Baltimore, pp 2574-2585

Lee I, Ouk Kim Y, Park S-C, Chun J (2016) OrthoANI: an improved algorithm and software for calculating average nucleotide identity. Int $\mathrm{J}$ Syst Evol Microbiol 66:1100-1103

Marshall IP, Berggren DR, Azizian MF, Burow LC et al (2012) The hydrogenase chip: a tiling oligonucleotide DNA microarray technique for characterizing hydrogen producing and consuming microbes in microbial communities. ISME J 6:814-826

Mokrane S, Bouras N, Meklat A, Lahoum A, Zitouni A et al (2016) Thermoactinomyces khenchelensis sp. nov., a filamentous bacterium isolated from soil sediment of a 
terrestrial hot spring. Antonie Van Leeuwenhoek 109:311-317

Na SI, Kim YO, Yoon SH, Ha SM et al (2018) UBCG: up-todate bacterial core gene set and pipeline for phylogenomic tree reconstruction. J Microbiol 56:280-285

Peters JW, Schut GJ, Boyd ES, Mulder DW et al (2015) [FeFe]and $[\mathrm{NiFe}]-$ hydrogenase diversity, mechanism, and maturation. Biochim Biophys Acta 1853:350-1369

Teng Y, Xu Y, Wang X, Christie P (2019) Function of biohydrogen metabolism and related microbial communities in environmental bioremediation. Front Microbiol 10:106

Tsilinsky P (1899) Sur les mucedinees thermophiles. Annales de l'Institut Pasteur 13:500-505

Wagner AO, Malin C, Lins P, Illmer P (2011) Effects of various fatty acid amendments on a microbial digester community in batch culture. Waste Manag 31:431-437

Wagner AO, Reitschuler C, Illmer P (2014) Effect of different acetate: propionate ratios on the methanogenic community during thermophilic anaerobic digestion in batch experiments. Biochem Eng J 90:154-161

Wagner AO, Markt R, Puempel T, Illmer P, Insam H et al (2017) Sample preparation, preservation, and storage for volatile fatty acid quantification in biogas plants. Eng Life Sci 17:132-139

Wagner AO, Janetschek J, Illmer P (2018) Using digestate compost as a substrate for anaerobic digestion. Chem Eng Technol 41:747-754
Wagner AO, Markt R, Mutschlechner M, Lackner N, Prem EM et al (2019) Medium preparation for the cultivation of microorganisms under strictly anaerobic/anoxic conditions. J Vis Exp 150:e60155

Watanabe S, Sasaki D, Tominaga T, Miki K (2012) Structural basis of $[\mathrm{NiFe}]$ hydrogenase maturation by Hyp proteins. Biol Chem 393:1089-1100

Yao S, Liu Y, Zhang M, Zhang X, Li H et al (2014) Thermoactinomyces daqus sp. nov., a thermophilic bacterium isolated from high-temperature Daqu. Int J Syst Evol Microbiol 64:206-210

Yoon JH, Kim IG, Shin YK, Park YH (2005) Proposal of the genus Thermoactinomyces sensu stricto and three new genera, Laceyella, Thermoflavimicrobium and Seinonella, on the basis of phenotypic, phylogenetic and chemotaxonomic analyses. Int J Syst Evol Microbiol 55:395-400

Yoon SH, Ha SM, Kwon S, Lim J et al (2017) Introducing EzBioCloud: a taxonomically united database of $16 \mathrm{~S}$ rRNA gene sequences and whole-genome assemblies. Int J Syst Evol Microbiol 67:1613

Publisher's Note Springer Nature remains neutral with regard to jurisdictional claims in published maps and institutional affiliations. 